\title{
ABSTRACTS
}

(This section of the JOURNAL is published in collaboration with the two abstracting journals, Abstracts of World Medicine, and Abstracts of World Surgery, Obstetrics, and Gynecology, published by the British Medical Association. The abstracts are divided into the following sections: syphilis (general, therapeutic, pathology); gonor rhoa (general, therapeutic, pathology); other venereal disease conditions; public health. After each subsection of abstracts follows a list of articles that have been noted but not abstracted. All subsections will not necessarily be represented in each issue.)

\section{SYPHILIS (General)}

The Chronic Paretic. Kirman, B. H. (1947). Lancet, 2, 755.

This is a commentary, based on a report of 42 cases, on the statement that is often made that fever therapy has tended to fill the mental hospitals with chronic paretics. The author's patients had been in hospital for 6 to 18 years. The average period of treatment was $11 \frac{1}{2}$ years. In all but 7 the cerebrospinal fluid was normal ; in 25 cases the blood Wassermann reaction was positive. Of the 42 patients 17 were good workers, 9 were fair, 15 did no work, and one was destructive. A euphoric mood was common. The author concludes that chronic paretics do not form a heavy burden on the community and should become fewer after the routine use of lumbar puncture, followed, where necessary, by suitable prophylactic treatment. A table shows the treatment given and the serological findings before and after treatment, together with the present mental state and working capacity.

E. W. Anderson

\section{SYPHILIS (Therapeutic)}

Cerebral Accidents during Penicillin Treatment of a Case of General Paresis. (Accidents encéphalitiques graves au cours du traitement par la pénicilline d'un cas de paralysie générale.) LEREBOULLET, J., and SAPINJalloustre, H. (1947). Bull. Soc. méd. Hôp. Paris., 4, 775.

A man, aged 40 , with a history of syphilis contracted 8 years earlier and of treatment with mercury, bismuth, and acetarsol, developed general paralysis. After a course of malaria therapy he improved sufficiently to go back to work. Three years later his mental condition again began to fail and he had difficulty in walking. He was admitted to hospital and was found to suffer from speech defects and pronounced disorientation. His gait was staggering, with increased tendon reflexes. His pupils were unequal and did not react to light, but otherwise there were no physical signs. He was given penicillin, 300,000 units a day, and had two violent convulsive attacks on the first and fourth days of treatment. The penicillin was stopped on the fifth day, and on the sixth he had a violent Jacksonian epileptic fit, starting in the left arm and the left side of the face. After the first attack he had a left hemiplegia which persisted for some time. This became less during a course of 28 injections of mercuric oxycyanide, but his psychical condition deteriorated. His general state became worse, with a rising temperature and a hypostatic pneumonia. He left the hospital and died a few days later.

The authors regard this as a form of Herxheimer reaction brought on by penicillin and causing a patch of softening in the brain. They think it better to combine penicillin with malaria therapy, and if the latter is contraindicated to start mercurial treatment before penicillin.

Reginald St. A. Heathcote

Penicillin Treatment of a Case of Amaurotic Tabes with Improvement. (Traitement par la pénicilline d'un cas de tabes amaurotique. Amélioration.) Guillain, G., Lereboullet, J., Sevileano, E., and Strauss, P. (1947). Bull. Soc. méd. Hôp. Paris, 4, 773.

A case of amaurotic tabes was considerably improved after treatment with penicillin. The patient gave a history of a sudden diminution of visual acuity about 8 months before he was admitted to hospital. He had a strongly positive Wassermann reaction and was treated with neoarsphenamine, and later with mercury and penicillin. His sight continued to deteriorate and he was admitted to hospital practically blind. $\mathrm{He}$ was found to be a typical tabetic with pin-point irregular pupils; his vision was limited to counting fingers at 30 in., and optic atrophy was present. He was given 400,000 units of penicillin a day and there was an almost immediate improvement in vision. On the tenth day his visual acuity had improved to $3 / 60$ and $6 / 60$, but there was no change in the ophthalmoscopic appearances. A total of 10 mega units was given, and a week after cessation of treatment the acuity had reached 6/30 in each eye. No further improvement with malaria therapy could be obtained. The authors do not claim that the improvement will necessarily be permanent.

\section{Reginald St. A. Heathcote}

Modern Treatment of Neurosyphilis. LesCHER, F. G., and RichaRDS, H. R. M. (1947). Brit. med. J., 2, 565.

During the past 8 years these authors have treated more than 50 patients with various forms of neurosyphilis by three different methods-25 with malaria and chemotherapy, 10 with penicillin alone, and 19 with malaria and penicillin; 47 have been followed up. Of 20 treated with malaria and chemotherapy, 6 were much improved, 6 improved, 4 unchanged, and 4 worse. Of these 1 still showed a strongly positive reaction in the cerebrospinal fluid (C.S.F.), 2 a weakly positive reaction, 7 an inactive fluid, and 10 a negative reaction. Their blood reactions were: 10 , negative ; 6 , improved; and 4 , positive. Of 10 patients treated with penicillin alone (4 mega units in oil given in doses of 125,000 units iwice daily), 4 were much improved, 3 improved, 2 unchanged, and 1 was worse. One showed a weakly positive reaction in the cerebrospinal fluid, 6 an inactive fluid, and 3 a negative reaction; blood reactions were 2 negative, 3 improved, and 5 positive. Of 19 patients 
treated with malaria and penicillin 9 were much improved, 5 improved, and 5 unchanged. The reactions in the C.S.F. were: 1 strongly positive, 1 weakly positive, and 7 negative, while in 10 cases there was an inactive fluid ; blood reactions were 6 negative, 2 improved, and 11 positive. It is concluded that penicillin and malaria together constitute the most effective treatment of active neurosyphilis, but if after 12 months the C.S.F. remains positive treatment should be repeated. All patients with late latent neurosyphilis should receive penicillin and malaria. In general, patients with meningo-vascular neurosyphilis did better than those with other forms, whatever the treatment adopted. [This is in accordance with expectation.]

T. O. Osmond

Penicillin in Neurosyphilis. Worster-Drought, C. (1947). Brit. med. J., 2, 559.

The author gives 40,000 units of penicillin by intramuscular injection in a watery solution every 3 hours for $7 \frac{1}{2}$ days, or occasionally 500,000 units once daily for 14 days, in cases of neurosyphilis, and in addition three injections of arsenic $(0 \cdot 3 \mathrm{~g}$. neoarsphenamine) and three of bismuth $(0.2 \mathrm{~g}$.) during the week of penicillin treatment. This is followed by twelve weekly injections of $0.45 \mathrm{~g}$. neoarsphenamine or $0.06 \mathrm{~g}$. " mapharsen" and $0.2 \mathrm{~g}$. bismuth at weekly intervals. Intrathecal injection of penicillin does not appear necessary; it may induce a brisk meningeal reaction with pyrexia and generalized pain, with a considerable rise in cells and protein in the cerebrospinal fluid. Cisternal injection is considered hazardous. Penicillin reactions are usually negligible, consisting mostly of mild pyrexia, but in view of the possibility of Jarisch-Herxheimer reactions it is recommended that 4 to 6 bismuth injections should be given before starting penicillin in cases of meningovascular or parenchymatous neurosyphilis.

The following methods of treatment are recommended : (1) In general paresis : 4 injections of bismuth, 4 to 5 mega units of penicillin in doses of 40,000 units every 3 hours, and induced malaria to 12 rigors followed by three " courses " of arsenic and bismuth (twelve injections of each per course). (2) In tabes : 4 to 5 mega units of penicillin followed by arsenic and bismuth in the usual dosage for 1 to 2 years. Fever therapy is not favoured. (3) In primary optic atrophy : 4 mega units of penicillin and 10 to 12 malarial rigors, followed by arsenic and bismuth till serological reactions become negative. (4) In late asymptomatic neurosyphilis : 4 mega units of penicillin at least and 10 to 12 malarial rigors, followed by arsenic and bismuth until the cerebrospinal fluid is normal and serological reactions are negative. [This latter seems a counsel of perfection, because in many of these cases blood reactions appear irreversible.]

In all cases of neurosyphilis the cerebrospinal fluid should be examined every 6 months until it becomes negative, and thereafter at yearly intervals for 2 years [preferably longer]. A clear distinction should be drawn between early and late asymptomatic neurosyphilis. The former usually reacts well to routine treatment but the latter should be treated just as energetically as general paresis. The full value of penicillin in neurosyphilis cannot be assessed for at least 5 years.

\section{T. E. Osmond}

Penicillin in Treatment of Neurosyphilis. DATTNER, B., Kaufman, S. S., and Thomas, E. W. (1947). Arch. Neurol. Psychiat., Chicago, 58, 426.

This study of 151 patients with active neurosyphilis treated with penicillin is based on experience at the
Bellevue Hospital, New York, where each year between 3,000 and 4,000 complete examinations of the spinal fluid are carried out. The authors' thesis that the spinal fluid findings afford the best guide to the activity of a syphilitic infection of the central nervous system and to the effect of treatment is now well known and receives an increasing degree of support. They are particularly strict in their definition of a pathological finding, and consider a cell count of anything above 4 lymphocytes to be abnormal. They also believe that an increase in total protein alone may indicate an active infection, as also may an abnormal colloidal gold curve, whereas the Wassermann reaction solely determines the specificity of the tests. As would be expected, the highest protein values were seen in patients with dementia paralytica, but the so-called paretic gold curves were found in many cases diagnosed as of asymptomatic neurosyphilis, meningo-vascular syphilis, and tabes dorsalis.

All the patients were given 40,000 units of penicillin intramuscularly 4-hourly, the total dosage varying from 2 to 9 mega units. Only 1 patient received 9 mega units, and experience has now led to the adoption of a uniform total dose of 6 mega units for all types of neurosyphilis. The response of 135 patients was satisfactory, including 3 general paretics who had previously been given malaria treatment and large amounts of arsenicals and bismuth without the spinalfluid cell counts reaching normal. Clinical improvement in all groups, including 31 out of 33 paretics, was satisfactory, comparing favourably with that following malaria therapy; the authors consider that penicillin will ultimately replace fever treatment.

[The paper is important and its seven tables will repay careful study in the original.

\section{G. L. M. McElligott}

Neurosyphilis: Treatment with Penicillin Alone and with a Combination of Penicillin and Malaria. Curtis, A. C., Burns, R. E., and Norton, D. H. (1947). Amer. J. Syph., 31, 618.

The authors treated 118 patients suffering from various forms of neurosyphilis, 75 with penicillin alone and 43 with penicillin and malaria, and observed them for 1 year or more. The total dose of penicillin was usually 4 mega units over $12 \frac{1}{2}$ days; with malaria treatment a temperature of $103^{\circ} \mathrm{F}$. $\left(39 \cdot 4^{\circ} \mathrm{C}\right.$.) was maintained for 50 hours or more. The patients included 15 with asymptomatic and 13 with meningovascular syphilis, 32 with tabes, 26 with taboparesis, and 32 with paresis. In general, those patients suffering from the severer forms received the combined treatment, so that a strict comparison between the two methods is not possible.

After penicillin alone $51 \%$ of the 118 patients showed clinical improvement and $62 \%$ improvement as judged by examination of cerebrospinal fluid, compared with 74 and $81 \%$ after combined treatment; if patients with asymptomatic neurosyphilis are excluded the percentages showing clinical improvement were 60 with penicillin and 80 with penicillin and malaria. In the 58 patients with paresis or taboparesis the percentages were 58 and 70 for penicillin alone and 64 and 71 for combined treatment, so that the latter was superior. Little difference was noted with the two forms of treatment in the 32 patients with tabes. Of 9 patients with primary optic atrophy, 8 were improved by one or other form of treatment. Five patients with " inactive" (Dattner-Thomas) cerebrospinal fluid failed to give negative Kahn reactions in the cerebrospinal fluid 1 year after either form of treatment. Comparisons with other series suggest that penicillin alone achieved as much in 1 year as malaria 
did in 3 years, and the combined treatment rather more. It is concluded that penicillin and malaria constitute the optimum treatment of neurosyphilis and that penicillin alone is indicated for patients who are not fit to stand malaria, especially certain cases of tabes.

\section{T. E. Osmond}

The Action of Small Doses of Penicillin in the Various Stages of Human Syphilis. (L'azione di piccole dosi di penicillina nei vari stadi della sifilide umana.) Bellone, A. G. (1947). G. ital. Derm. Sif., 88, 552.

The author treated patients who had had no previous treatment and had clear manifestations of the various stages of syphilis with small doses of penicillin by intradermal or intramuscular injections. The penicillin was given either in divided doses (800 to 1,000 Oxford units every 2 hours up to 5,600 to 8,000 units) or by a single intramuscular injection of 5,000 to 8,000 Oxford units. General and local reactions of the Herxheimer type developed in patients with recent cutaneous primary and secondary lesions, but not in those whose syphilomata were not more than 2 weeks old or who had hypertrophic papules limited to the mucous membrane. There was diminution in the movement and number of spirochætes; they disappeared from the surface of the lesions in those patients who developed an intense Herxheimer reaction. The lesions improved rapidly. The improvement was less marked in the primary sore, but was pronounced in the recent and late secondary cutaneous lesions and in the tertiary lesions. With very few exceptions the serological reactions were unaffected. The method of administration did not influence substantially the clinical results; however, the most intense reactions did tend to occur with divided doses.

In 1 case of secondary-tertiary dermal syphilis, after injecting 1,000 Oxford units of penicillin every 3 hours for a month (a total of 250,000 Oxford units), the author observed, 2 months after the completion of treatment and in the absence of any other specific treatment, not only the disappearance of the objective cutaneous signs but also the return to negative of the serological reactions.

The author concludes that the Treponema pallidum in the human organism is one of the most penicillinsensitive pathogenic agents and that small doses suffice to arrest its development and kill it. The mechanism of action of these small doses may perhaps be to stimulate the specific defences of the organism by the vaccinating action of the spirochætes which are killed.

\section{G. Lorriman}

Penicillin Therapy in Early Syphilis. III. ARNOLd, R. C., MAhoney, J. F., Cutler, J. C., and Levitan, S. (1947). J. invest. Derm., 9, 269.

This report cov̄ers an observation period of from 6 to 30 months on a large series of patients treated for early syphilis with 85 intramuscular injections of penicillin (total dosage, 3,400,000 units). Commercial penicillin was used throughout, and injections were given at 2hourly intervals, studies of penicillin concentration in blood serum having indicated that this interval might be more efficacious than the more usual 3-hourly one in maintaining a uniform blood level. Approximately 67\% of 728 patients showed primary lesions only, the remainder being in the secondary stage of the disease. The serological response to treatment was checked by seven different tests; end-point quantitative determinations were made by the methods of Kahn and Mazzini. Over $50 \%$ of the patients were observed for more than 183 days and just under $40 \%$ for a full year. The spinal fluid was examined before treatment in 458 patients, in 34 of whom some slight deviation from the normal was noted. Cerebrospinal fluid was examined after treatment in 230 patients, with negative results in all but 3 ; in the latter the fluid had been abnormal before treatment. Only 17 patients showed signs of clinical or serological relapse; 14 of these had clinical evidence of early syphilis (muco-cutaneous lesions). An increasing proportion of patients in each treatment period became serumnegative as the duration of the post-treatment period lengthened. No instances of central nervous system involvement were noted.

G. L. M. McElligott

Two Reports on Out-patient Attendance for Treatment of Syphilis, using Penicillin in Oil-beeswax. I. A Study of Clinic Attendance. HAYMAN, C. R. (1947). J. vener. Dis. Inform., 28, 221.

In spite of the continuing popularity in many parts of the United States of the Rapid Treatment Centres for the in-patient treatment of early syphilis with penicillin, the author believes that there is no medical need for admission to hospital when daily injections of penicillin in oil-beeswax suspension are given. The purpose of this study was to find out whether patients would, in fact, report daily for treatment as ordered. Three different schemes of treatment were used, one lasting 6 days, a se ?ond 7 , a third 8 , and a fourth 10 days. Of 50 patients $\sim$ the 6 -day scheme, only 1 failed to complete the course as ordered; among 22 patients on the 7- and 8-day courses there were no defaulters, and of 35 on the 10-day course 9 missed 1 day and 3 missed 2 . In no case did any patient receive less than 2.4 mega units of penicillin.

G. L. M. McElligott

The Effectiveness in Experimental Syphilis of Penicillin in Peanut Oil-Beeswax given in Sixteen Daily Injections. Fleming, W. L., and Holcombe, M. W. (1948). Amer. J. Syph., 32, 53.

To help in evaluating the relative efficacy of penicillin in peanut oil-beeswax in the treatment of syphilis the authors administered 16 daily injections to rabbits with early syphilis. Seven groups of 10 rabbits were inoculated with the Nichols strain of Treponena pallidum in both testes, and treated 8 weeks after inoculation with total doses of $250,500,1,000,2,000,4,000,8,000$, and 16,000 units per kilo body weight. The criteria of cure depended on results of dark-ground examinations of initial and of recurrent lesions, and on the finding of negative lymph-node transfers after 6 months, the recipient animals being kept under observation for 4 months. In the first three groups-that is with a total dose of up to 1,000 units-only 1 rabbit was cured. With 2,000 units 7 were cured out of 8 ; in the last three groups-with $4,000,8,000$, and 16,000 units-all were cured. Thus the CD50 (dose necessary to cure $50 \%$ of rabbits) was between 1,000 and 2,000 units per kilo body weight. The penicillin concentrations in the suspensions used were necessarily lower than those in the " Romansky formula," and this may have influenced the CD50 unfavourably. T. Anwyl-Davies

A Joint Report on a Cooperative Investigation of the Efficacy of Species of Penicillin in the Treatment of Experimental Syphilis. ARNOLD, R. C., BOAK, R. A., Carpenter, C. M., Chesney, A. M., Fleming, W. L., Gueft, B., Mahoney, J. F., and Rosahn, P. D. (1947). Amer. J. Syph., 31, 469.

This paper deals with the earliest American works at six centres on the subject of the penicillin fractions and 
experimental syphilis. The penicillins used consisted mostly of $G, F, X$, and $K$, though one specimen labelled as $90 \%$ F proved on assay to contain only $65 \%$. Groups of 10 rabbits, inoculated with the Nichols strain of Treponema pallidum, were given after 6 weeks $500,1,000$, $2,000,4,000,8,000$, or 16,000 units per $\mathrm{kg}$. of one of the different penicillins. They were then observed for 120 days, after which lymph-node transfer was performed on the apparently healthy animals and the observation period was extended for a further 4 months. The CD 50 dose for penicillin $F$ was 5,200 to 20,800 units per $\mathrm{kg}$. ; for $G 1,000$ to 2,000 units; 16,000 units of $K$ per $\mathrm{kg}$. failed to cure half of the animals. Results with $X$ varied with different workers. It is concluded that $G$ is the most potent penicillin and that six times the dose of $F$ is required to produce the same result. The data were insufficient to decide the relative merits of $F, K$, and $X$.

\section{R. R. Willcox}

Reinfection in Experimental Syphilis in Rabbits following Penicillin Therapy. II. Reinfection in Early Latent Syphilis. ARNOLD, R. O., MAHONEY, J. F., and Cutler, J. C. (1947). Amer. J. Syph., 31, 489.

All of 34 rabbits inoculated with the Nichols strain of Treponema pallidum developed scrotal chancres, which were allowed to heal without treatment, the animals being then observed for 8 months before being given 300 units of sodium penicillin per kilo-double the dose previously found effective in early infections and early latent rabbit syphilis-in 48 2-hourly injections. After an interval of 10 days the rabbits were once more inoculated with the Nichols strain. The animals were observed for 4 months and, none having developed local lesions, inguinal and popliteal lymph-node transfers were made from all. The new animals were observed for 100 days, during which time $18(53 \%)$ developed syphilis. The non-appearance of local lesions in the re-inoculated rabbits of this series contrasts with the results of previous experiments with early infectious syphilis by the same authors, when $27 \%$ of those re-inoculated after treatment developed dark-field positive lesions and $73 \%$ a symptomless infection, as proved by later lymph-node transfer.

The authors conclude that many so-called relapses in human subjects are in effect re-infections and that the immune factors in early latent syphilis are more potent than those obtained in early infectious syphilis.

\section{R. R. Willcox}

Comparative Effectiveness of Penicillins G, F, K, and $X$ in Experimental Syphilis as Determined by a Short in vivo Method. TURNER, T. B., CUMBERLAND, M. C., and LI, H-Y. (1947). Amer. J. Syph., 31, 476.

The authors employed spirochæte counts in assessing the relative effectiveness of the penicillin fractions. Rabbits were inoculated intracutaneously at 9 or 10 sites on the back with $0.1 \mathrm{ml}$. of a testicular emulsion containing the Nichols strain of Treponema pallidum. Syphilomata developed after 2 or 3 weeks and rabbits showing lesions approximately equal in size were selected for the tests. An initial count of the treponemata in 200 oil-immersion fields of dark-field specimens taken from 2 rabbits, after slicing the syphiloma with a razor, was then performed; counts of 200 or more were considered satisfactory. The average initial counts in those rabbits subsequently to be given penicillins $\mathbf{G}$, $F$, and $K$ averaged 1,000 and that of $X$ was as high as 1,714. Two or 3 rabbits each were treated on one of 8 dosage schedules-the highest dose being $2 \mathrm{mg}$. per $\mathrm{kg}$. administered intramuscularly in three 2-hourly doses of the crystalline penicillins $\mathrm{G}, \mathrm{F}, \mathbf{X}$, or $\mathrm{K}$. Post-treatment spirochæte counts were made after 24 hours.

The reduction in the spirochæte count was in direct proportion to the size of the dose and considerably smaller amounts of penicillin $G$ were required to give the same results as did $F, X$, and $K$, the latter showing decreasing activity in the order named. A standard effective dose (E.D.) is defined as that which reduces the count to 10 or less per 200 fields. Expressing the ED 50 dose of $G$ as 100 , those of $F, K$, and $X$ were 17 , $<5.5$, and 9 respectively. Expressed in Oxford units, the ED 50 curative values were : for $\mathrm{G}, 183 ; \mathrm{F}, 1,024$; $\mathrm{K},>4,380$; and $\mathrm{X}, 1,054$.

R. R. Willcox

The Therapeutic Activity of Streptomycin in the Infection Caused by Treponema pallidum in the Mouse. (L'activité thérapeutique de la streptomycine dans l'infection produite chez la souris par le Treponema pallidum.) Drouhet, E. (1947). C. R. Soc. Biol. Paris, 141, 1016.

In the syphilitic infection of the mouse produced by $T$. pallidum a single dose of 10,000 units was insufficient but complete sterilization was obtained by a total dose of 25,000 to 35,000 units given over 5 days, at least 5,000 units being given daily. Penicillin cures the infection after a dose of 15,000 units.

G. M. Findlay

The Evaluation of Antibiotics by the Prevention of Experimental Syphilis. RAKe, G., DUNHAM, W. B., and Donovick, R. (1947). J. infect. Dis., 81, 122.

The usual evaluation of antisyphilitic remedies is a long and costly procedure involving a period of 11 months. The authors' methods are : (1) A given number of spirochætes is rubbed into an incision on the back of a rabbit, and after 4 hours an injection of the remedy to be tested is given. In the case of rabbits showing no lesions after 4 months, lymph-node transfers are made and the recipient rabbits observed for 2 months longer. (2) A second technique consists in injecting $0.1 \mathrm{ml}$. of a suspension of spirochætes, 1 to 5 per field, intradermally into each of 2 sites on the clipped back of a rabbit. Treatment consists of twenty-four 4-hourly intramuscular injections, starting 3 days later. (3) A third technique is similar to the second, but 60,000 spirochætes are given in each injection, and treatment is started after 6 hours.

The mean incubation period with method 1 was 24.3 days and 12 days with methods 2 and 3 ; in all cases the period was increased by penicillin. A comparison of the three techniques showed that it was not necessary to transfer lymph nodes, and the validity of results was as good after $2 \frac{1}{2}$ months with methods 2 and 3 as it was after 6 to 10 months with method 1 . Experiments were carried out with various penicillins by method 1.; the activity of the material varied inversely with the purity. With methods 2 and 3 various penicillins were tested; the PD 50 (\% prophylactic dose) could be achieved with $0.1 \%$ of the amount of penicillin needed for a CD 50 (\% curative dose) with technique 1 , and the period was much shorter. Some of the results obtained with methods 2 and 3 are as follows: The PD 50 of penicillin $G$ is 109 units per kg. of rabbit, of $X 173$, of $K 645$, and of mixtures of $F$ and dihydro-F 170 to 310 ; certain impurities appear to enhance the effect of penicillin, though the reason for this is obscure. Streptomycin is effective, but only in relatively enormous doses $(135,000$ units per $\mathrm{kg}$.) ; when combined with penicillin it has only an additive effect.

The results reported apply to prevention rather than cure, but they are considered to be none the less valid on that account. A point of considerable interest is 
that the PD 50 is about one-fifteenth of the CD 50, and therefore the dosage commonly used in gonorrhœa may be expected to cure a considerable proportion of syphilitic infections in the prodromal stage. When, therefore, a double infection is suspected, an increase in the dosage for gonorrhœa might well be effective in eradicating both diseases.

T. E. Osmond

\section{A Preliminary Report on a New and Simplified Penicillin Vehicle. GOODFRIEND, M. J., FISCHER, I. C., and Caruso, L. J. (1948). N. Y. St. J. Med., 48, 192.}

Trials were made with "solvecillin," an emulsion of cholesterol esters with $1 \%$ beeswax, as a vehicle for the intramuscular injection of crystalline penicillin. The desired volume of emulsion is introduced by syringe into the vial of dry penicillin, the container is agitated slightly, and the contents are withdrawn through a 20-gauge needle and injected in the usual way. Twenty patients received 100,000 units in $2-\mathrm{ml}$. emulsion, 35 received 200,000 units in $2-\mathrm{ml}$. emulsion, 8 received 500,000 units in 3-ml., and 7 in 4-ml. emulsion. Mean results for the various groups are summarized in the table. Details of the scatter of individual results are not given.

Blood penicillin levels

\begin{tabular}{|c|c|c|}
\hline \multirow[b]{2}{*}{ Dose Received } & & \\
\hline & $0 \cdot 1$ unit/ml. & $0.06 \mathrm{unit} / \mathrm{ml}$ \\
\hline $\begin{array}{l}100,000 \text { units ( } 20 \text { patients) } \\
200,000 \text { units }(35 \text { patients) } \\
500,000 \text { units ( } 15 \text { patients) }\end{array}$ & $\begin{array}{c}8 \text { hours } \\
10 \text { hours } \\
\text { (not stated) }\end{array}$ & $\begin{array}{l}12 \text { hours } \\
18 \text { hours } \\
>24 \text { hours }\end{array}$ \\
\hline
\end{tabular}

A mild urticarial rash was observed in one patient but this was controlled with " benadryl." Injection abscess was not seen in any case in this series. G.I.C. Ingram

\section{SYPHILIS (Pathology)}

"Liquid" versus "Solid" Penicillin in Oil and Wax. The Effect of Particle Size and Type of Penicillin. Dowling, H. F., Romansky, M. J., WeLCH, H., Robinson, J. A., Chandler, V. L., Zeller, W. W., and Hirsh, H. L. (1947). J. Amer. med. Ass., 135, 567.

A single intramuscular dose of 300,000 units of penicillin in $1 \mathrm{ml}$. of $4.8 \%$ beeswax in oil was given to 252 patients. The preparations, made up by 11 different manufacturers, included sodium and potassium crystalline salts and amorphous calcium salts, in both " solid" (that is, at room temperature) and "liquid" (fluid at room temperature) forms. Preparations found to contain $50 \%$ or more of the "total relative weight" of particles of penicillin of greater diameter than $50 \mu$ were classed as " large particle preparations" ; the remainder were termed "small particle preparations." Blood samples were withdrawn at $12,16,20$, and 24 hours after the injections, and parallel penicillin assays were made by a modified Rammelkamp method and by the Bacillus subtilis opacity technique of Randall and others ( a control being used to eliminate the effects of anti-subtilis factors in the blood other than penicillin). The height of blood levels found is not given; the results are classified according to whether or not " measurable blood levels" could be detected at the various sampling-times ; in all cases it appears that on this basis the "subtilis " method is the more sensitive of the two. "Measurable blood levels" were found in a higher proportion of patients when crystalline preparations had been given than when the amorphous form had been used. "With the "liquid " preparations the "large particle preparations" gave higher percentages in each sampling after the first than did the "small particle preparations." With "solid" preparations the 24-hour readings for the " large particle preparations " show a slight superiority over those for "small particle preparations," but at the other times there is little difference between the two groups. The results with the "liquid " "large particle "preparations are much the same as those obtained with the "solid" preparations of comparable particle size. It is therefore concluded that a "large-particle" "liquid " injection prepared from a crystalline salt is the preparation of choice.

[It would be interesting to know if the injections were all made at the same time of day, as the renal secretion of penicillin is believed to be less by night than by day. Other relevant information would be the highest blood levels found, and a comparison of the variations in blood levels shown by the different preparations.]

$$
\text { G. I. C. Ingram }
$$

A New Penicillin for Prolonged Blood Levels. Sullivan, N. P., SYmmes, A. T., Miller, H. C., and Rhodehamel, H. W. (1948). Science, 107, 169.

A new crystalline penicillin has been prepared by combining procaine with penicillin $G$. The crystals have a solubility of approximately 7,000 units per $\mathrm{ml}$. in oil, oil-and-water emulsion, or physiological saline : they contain not less than $90 \%$ penicillin $G$ with a potency of 940 units per mg. (1,040 units per mg. theoretical). After intramuscular injection the blood level is said to remain elevated for a considerable period. This is correlated with the fact that at least $50 \%$ of the total weight of the particles are $50 \mu$ or more in length. The greater the size of the penicillin particles the slower is said to be the rate of absorption. G. M. Findlay

The Increase of the Antibacterial Effect of Penicillin through "Pyramidon." (A penicillin bacteriumellenes hatásának növelese pyramidonnal.) DuCKs, G., and Mosonyı, L. (1948). Orv. Lapja, 4, 74.

"Pyramidon" (amidopyrine) 0.3 g., given simultaneously with penicillin raises the level of the latter in the serum. The effective level of penicillin can be maintained for 5 to 6 hours with repeated doses of pyramidon. The effectiveness of penicillin dissolved in beeswax is also increased through pyramidon. In certain circumstances when 3-hourly injections of penicillin are impracticable, pyramidon may maintain the effective concentration over a longer period.- - [From the authors' summary.]

A Method for Producing Sustained High Penicillin Levels in the Blood. KING, F. H., SchneIrson, S. S., Sussman, M. L., JanOwitz, H. D., and Blum, L. (1947). Proc. Soc. exp. Biol., N.Y., 66, 548.

High levels of penicillin in the blood were obtained by the simultaneous injection of large doses of crystalline penicillin and caronamide. Caronamide is $4^{\prime}$-carboxyphenylmethanesulphonalide and has been shown to have an inhibitory effect on the renal tubular excretion of penicillin. Preliminary experiments in dogs demonstrated that the penicillin levels in the aorta produced by the rapid injection of a concentrated solution into the brachial vein were as great as those obtained by introducing the penicillin direct into the right side of the heart. No untoward effects occurred even when 
$1,000,000$ units of crystalline penicillin dissolved in $5 \mathrm{ml}$. of distilled.water were injected into the brachial vein of a dog.

Penicillin levels were then studied in the blood of 9 patients after the intravenous administration of up to 10 mega units of crystalline penicillin during a period of 10 hours. The solutions were injected rapidly into the right antecubital vein, the injection being completed within 5 seconds. No clinical or electrocardiographic abnormalities were noted. The caronamide was given in a dose of $4 \mathrm{~g}$. by mouth every 3 hours day and night, starting 24 hours before treatment with penicillin and continuing throughout the period of observation. Without caronamide the blood levels immediately after the injection of 1 mega unit of penicillin varied between 88 and 136 units per ml. ; with caronamide the levels were 152 to 184 units per ml. At the end of 1 hour with penicillin alone the blood levels varied from 8 to 16 units per $\mathrm{ml}$., and with caronamide the blood levels varied from 40 to 64 units per $\mathrm{ml}$. The differences were even more pronounced when repeated injections of penicillin - were given. After ten injections, for example, 2 patients receiving caronamide and 1 mega unit of penicillin in each injection had blood levels of 256 to 280 units per $\mathrm{ml}$. immediately after the tenth injection, and 200 to 208 units per ml. 1 hour later. With penicillin alone the comparative values were 120 and 16 units per $\mathrm{ml}$. No toxic effects were noted in any of the cases studied.

R. Wien

Anomalous Findings in Penicillin Level Determinations in Urine. FALK, C. R., and BLECH, H. (1947). J. Lab. clin. Med., 32, 1356.

Urine samples were collected at intervals after intramuscular injection of penicillin into patients treated for syphilis. The bactericidal activities of 249 specimens of urine collected more than 4 hours after the injection were of the anticipated order, but in 67 specimens collected within 4 hours of injection the bacfericidal activity was far greater than expected. Such activity increased during storage of the urine for up to 6 weeks and then declined. The activity present in $1 \mathrm{ml}$. of urine often exceeded that of the total dose of injected penicillin. The usual technical errors were carefully controlled. No explanation is offered for these findings. Derek R. Wood

Relation Between Thiamine and Arsenical Toxicity. Preliminary Report. SeXtoN, G. B., and Gowdey, C. W., (1947). Arch. Derm. Syph., Chicago, 56, 634.

Arsenical encephalopathy has a high mortality rate. None of the theories advanced to explain this cerebral syndrome is completely satisfactory. The present authors favour the view that it results from interference with cellular function by the combination of arsenic with the cellular sulphhydryl (SH) groups associated with enzyme proteins. They draw attention to the similarity between the clinical and pathological findings in arsenical encephalopathy and acute vitamin- $B_{1}$ deficiency (Wernicke's syndrome); their table lists 17 points of correspondence. Aneurin influences carbohydrate metabolism. It is needed, in the form of diphosphate ester, for the oxidative removal of pyruvic acid and, indirectly, of lactic acid. During aneurin deficiency lactic and pyruvic acids accumulate in the blood and tissues, and there is increased urinary excretion of pyruvic acid and other alpha-keto-acids.

The authors have carried out biochemical studies in dogs and in 13 syphilitic patients receiving intensive 5-day therapy with mapharside by intravenous drip. A significant upset in carbohydrate metabolism was found with increased pyruvic acid and sugar in the blood. This upset in carbohydrate metabolism was greatest where there were clinical signs of toxicity, and the sudden rise on the level of pyruvic acid, associated with increased muscular sensitivity and rising temperature, is evidence of severe toxicity (the methods of biochemical investigation used and a quantitative method for estimating muscular sensitivity are given). Intravenous administration of aneurin produced clinical improvement in 2 cases of arsenical encephalopathy, but in one the improvement was only temporary. Another patient, who was found to have a subacute aneurin deficiency, was given aneurin intravenously and subsequently received the 5-day-drip treatment without ill effect. Aneurin may thus have a prophylactic value as well as being indicated, in association with BAL, in the early treatment of arsenical encephalopathy.

[This interesting paper, which should be read in the original, may be an important contribution if the findings reported are confirmed by further studies.]

\section{S. M. Laird}

Experimental and Clinical Studies on Oral Bistrimate (Sodium Bismuth Triglycollamate) for Systemic Bismuth Therapy. Lehman, R. A., and FASSET, D. W. (1947). Amer. J. Syph., 31, 640.

"Bistrimate" (sodium bismuth triglycollamate) has a bismuth content of $18.3 \%$; one g. therefore contains $0.138 \mathrm{~g}$. of metallic bismuth and $0.823 \mathrm{~g}$. of disodium triglycollamate. The drug is readily soluble in water, giving a neutral solution. The acute and chronic toxicity of bistrimate were studied on various experimental animals, and the toxicity was found to depend primarily on the amount of bismuth metal. In cats some lesions were found in the upper colon but were not related to the dosage ; rabbits showed no toxic signs until a dose of $106 \mathrm{mg}$. per kilo was reached, when diarrhœa occurred; the only signs in dogs were seen in the intestinal tract when doses were large. Disodium triglycollamate was not toxic for mice in doses up to $250 \mathrm{mg}$. per kilo.

It appears that a relatively small percentage of bistrimate is absorbed; some is excreted in the urine and the amounts found in liver and kidneys were in accordance with expectation. Bistrimate was administered to 15 " normal " hospital patients, to some for over a year ; dosage reached the equivalent of $450 \mathrm{mg}$. of bismuth daily in many cases, and was followed by a urinary excretion of 2 to $4 \mathrm{mg}$. of bismuth or more ; toxicity was negligible. Bistrimate had no effect on the clotting time of the blood. Five patients with syphilis, 2 with early and 3 with late lesions, reacted as would be expected with systemic bismuth.

It is concluded that bistrimate affords a safe and convenient method of administering bismuth, especially as deposits of the metal are not formed and excretion drops rapidly when the drug is discontinued.

\section{T.E. Osmond}

Attempted Immunization of Rabbits Against Syphilis with Killed Treponema pallidum and Adjuvants.

Magnuson, H. J., Halbert, S. P., and Rosenau, B. J. (1947). 'J. vener. Dis. Inform., 28, 267.

Acute syphilomata of rabbit testes were removed 14 to 17 days after inoculation of $10,000,000$ organisms into each testis. After the material had been minced, mixed with normal rabbit serum, and centrifuged, the 
supernatant fluid, after counting the spirochætes, was frozen at $-80^{\circ} \mathrm{C}$. and lyophilized before use. The adjuvants employed were Mycobacterium phlei with the mineral oil and lanolin derivative "falba," forming an emulsion containing 80,000,000 Treponema pallidum and $2 \mathrm{mg}$. of dried Myco. phlei per ml. One group of animals received 600 to 800 lyophilized spirochætes without adjuvants in 6 to 8 weekly subcutaneous injections. In the group with adjuvants immunization commenced with similar schedules but local ulceration with loss of antigen compelled completion of the injections by the intramuscular route, and some $280,000,000$ organisms were given to each animal. Cardiolipin flocculation tests were performed weekly on blood taken from the ear, and node transfers made from a few of the inoculated animals indicated that the antigen was not infective. Challenge injections of $T$. pallidum were made 11 to 16 weeks after the first inoculation of the antigen. In both groups syphilis developed in proportion to the size of the inoculum in a ratio similar to that in untreated rabbits. A number of animals in both groups, however did develop a positive serological test.

\section{R. R. Willcox}

The Minimal Infectious Inoculum of Spirochæta pallida (Nichols Strain), and a Consideration of its Rate of Multiplication in Vivo. MAGNuSON, H. J., Hill, C., Eagle, H., and Fleischman, R. (1948). Amer. J. Syph., 32, 1.

In experimental syphilis the incubation period is a function of the number of organisms inoculated. The authors controlled the size of the inoculum of Treponema pallidum in rabbits, determined the effect of graded inocula on the incubation period, and thereby estimated the rate of multiplication in vivo of $T$. pallidum. The results of intracutaneous inoculation at a single site were almost identical with those of inoculation at multiple sites. An inoculum of 200,000 organisms was regularly infectious, with an average incubation period of 14.3 days. As the size of the inoculum decreased there was a progressive increase in the incubation period and a rising percentage of inoculation failures. With the Nichols strain of $T$. pallidum, an inoculum of 200,000 organisms produced a dark-field positive lesion in $100 \%$ of cases. This decreased to $92 \%$ with 20,000 organisms, $93 \%$ with 2,000 organisms, $88 \%$ with 200 organisms, $71 \%$ with 20 organisms, and $47 \%$ with 2 organisms. With each tenfold decrease in the size of the inoculum there was a progressive increase in the incubation period $(17,27,27,32,35$, and 36 days with inocula of 20,000 , $2,000,200,20,2$, and 1 spirochætes respectively). This average increase of $4 \cdot 1$ days with each successive tenfold decrease in the number of spirochætes inoculated suggests that the organisms require $4 \cdot 1$ days to multiply tenfold and thus compensate for the difference in size of inoculum. If each spirochæte divides into two spirochætes, there were $3 \cdot 3$ divisions in the $4 \cdot 1$ days $\left(2^{3 \cdot 3}=10\right)$, which gives an average of 1.24 days or 30 hours for each division in rabbit syphilis. When aqueous penicillin was given every $2,4,8$ to 16 , or 24 hours, the optimum interval between injections, permitting cure with the smallest amount of penicillin, was 8 to 16 hours. Injections at 24-hour intervals were much less effective. This suggests that organisms damaged but not killed may recover if too long an interval is allowed between injections, or that the organisms may multiply sufficiently between injections to counteract the therapeutic action of the drug. Intratesticular inoculation, however, of only one or two spirochætes sufficed regularly to initiate infection, and the incubation period did not vary continuously with the size of the inoculum. Possibly a difference in local tissue susceptibility and some local defence mechanism operating in the skin raise the threshold for infection when compared with that of the testicle where the organisms may find a more favourable environment for survival.

T. Anwyl-Davies

The Effect of Antisyphilitic Treatment on the Microscopic Appearance of Syphilitic Aortitis. WeBSTER, B., and Reader, G. G. (1948). Amer. J. Syph., 32, 19.

The microscopical appearances of syphilitic aortitis at necropsy on 45 subjects were compared with the clinical records of the patients' treatment in the New York Hospital. The degree of inflammation was recorded on a rating scale according to the amount of lymphocytic infiltration, the presence of plasma cells, and the amount of perivascular infiltration and endarteritis. The patients were divided into three groups according to whether they had received "adequate," " inadequate," or no treatment. The minimum " adequate" treatment was considered to be approximately 20 arsenical and 20 bismuth injections, an amount which might be considered sufficient for other forms of visceral syphilis. All the 19 untreated cases had an active syphilitic process, as shown by an active cellular infiltration of the aorta, while only 3 of 19 adequately treated cases revealed an active type of syphilitic aortitis. No correlation was demonstrable between the duration of the infection and activity in the aorta. Hence, adequate specific therapy does profoundly modify the inflammatory process of syphilitic aortitis.

T. Anwyl-Davies

Arsenical Encephalopathy in Indian Troops. KRAINER, L., BlaCK, D. A. K., MCGILl, R. J., and RAO, N. V. (1947). J. Neurol. Neurosurg. Psychiat., 10, 171.

A high incidence of arsenical encephalopathy was noted in 1943 and 1944 in Indian troops undergoing neoarsphenamine (N.A.B.) treatment for syphilis. This increased incidence was considered to be due to the giving of injections of N.A.B. twice a week instead of once a week. Malaria during or immediately before N.A.B. treatment was an important factor in increasing the incidence of arsenical encephalopathy. The onset was at times acute, with an epileptic fit as the presenting symptom; in others there was initially general malaise and headaches for a few days. There were four stages: (1) mild confusion and mental retardation with lethargy ; (2) drowsiness, lack of co-operation and extensor plantar responses ; (3) pyrexia, stupor, incontinence, and frequent fits ; (4) deep coma. Patients could recover from the first three stages, but all those who reached the fourth stage died. The protein content of cerebrospinal fluid was raised and the amount was of prognostic value because no patient with a protein content of over $300 \mathrm{mg}$. per $100 \mathrm{ml}$. recovered.

Pathologically the most constant change in the brain was congestion and stasis, involving particularly the veins and arterioles of the white matter and brain stem, and a viscous exudation of plasma around veins and arteries was fairly constant. Hæmorrhages were scanty, in contrast to the classical hæmorrhagic arsenical encephalopathy. Oedema was also not conspicuous. Perivascular round-cell infiltration was common and was thought to be due to syphilis rather than to the encephalopathy.

The authors think that the condition is due to a relatively high level of N.A.B. causing vascular damage with loss of selective permeability of the vessel walls. 
Because of this N.A.B. and split products of N.A.B. penetrate into the nervous tissue and interfere with the oxidation systems of the parenchyma. In classical hæmorrhagic cases the vascular damage is more prominent in the form of hæmorrhage and œdema ; in non-hæmorrhagic cases, such as those commonly seen in Indian troops, the invisible toxic effect on the parenchyma is the important factor.

$$
\text { J. W. Aldren Turner }
$$

\section{GONORRHOEA (General)}

"Penicillin-resistant Gonorrhea" vs. "Non-specific Urethritis." PARKHURST, G. E., HARB, F. W., and Cannefax, G. R. (1947). J. vener. Dis. Inform., 28, 211.

Investigation of the possibility that certain strains of Neisseria gonorrhoea become penicillin-resistant in vivo were made by studying a group of patients labelled as suffering from " penicillin-resistant gonorrhœa." Most of these were found by culture to have non-specific infections due to various micro-organisms : diplococci, staphylococci, streptococci, bacilli, diplobacilli, trichomonads, and diphtheroids. Not uncommonly, a mucoid or purulent discharge persists after patients have been treated with intensive penicillin therapy. The authors failed to demonstrate gonococci by culture from these discharges and believe that they are due to non-gonococcal or "non-specific" infections. Irrigations with acriflavine, "mercurochrome," " argyrol," " protargol," and potassium permanganate gave unsatisfactory results. Except for a few cases of Reiter's disease, however, the most persistent discharges disappeared after irrigation with streptomycin solution $(1$ in 1,000$)$ three times daily for 2 days. Those found to have gonorrhoa were bacteriologically cured with penicillin therapy. The majority had one injection of 300,000 units in $1 \mathrm{ml}$. of peanut oil with $4.8 \%$ beeswax; a small percentage required 2 such injections, a day apart ; and complicated cases were given 3 daily injections as a routine. In a series of 2,821 cases of male and female gonorrhca not a single instance was encountered in which adequate penicillin dosage did not render the patient culturally free from the gonococcus. Pure-culture, carbohydratetest-confirmed strains suspected of being resistant to penicillin concentrations usually maintained in vivo should be subjected to penicillin-tolerance tests before a diagnosis is made of " penicillin-resistant gonorrhœa." - [Authors' summary.]

\section{GONORRHOEA (Therapeutic)}

Penicillin in 1\% Beeswax-Arachis Oil. BrIndLe, $H$. FAIRBROTHER, R. W., and JACKSON, F. B. (1947). Lancet, 2, 505.

Some years' study of slow-release vehicles indicated that, to obtain the maximal prolongation of the effect of a drug, the volume injected should be small, 0.5 to $1 \mathrm{ml}$. being the optimum bulk. Preliminary tests on rabbits showed that no significant difference existed between a plain oil vehicle and one containing 4 to $5 \%$ of beeswax. Later tests demonstrated that 1\% beeswax in arachis oil was an excellent vehicle for crystalline penicillin. Although the addition of beeswax to the oil was of little benefit in maintaining an effective penicillin level in the blood, its inclusion had the pharmaceutical advantage of distributing and diffusing the penicillin in the oil more satisfactorily. A mixture, perfectly fluid at ordinary temperatures and sufficiently non-viscous to pass through a moderately fine needle, was prepared with $30,000,000$ units of pure non-hygroscopic sodium penicillin, $1 \mathrm{~g}$. beeswax, and arachis oil sufficient to produce. $100 \mathrm{ml}$. Assays of the blood level after the intramuscular injection of this preparation of 300,000 units in $1 \%$ beeswax-arachis oil revealed that the penicillin levels in serum were maintained for 15 hours, compared with 8 to 10 hours for the same dose in aqueous solution. With a No. 2 serum needle the same dose was given to 28 proved cases of acute gonorrhœa, 20 in males and 8 in females. There was clinical cure in all cases, without complaint of pain or local reaction. T. Anwyl-Davies

Penicillin in Oil and Wax in the Treatment of Gonorrhoea in Women. Fraser, F., and LOME, L. (1947). Canad. J. Publ. Hlth., 38, 484.

The authors treated 133 women suffering from gonorrhœa with a single intramuscular injection of calcium penicillin in pea-nut oil and $4.8 \%(\mathrm{w} / \mathrm{v})$ beeswax. Most of the women were between 17 and 23 years of age and had been infected for about 1 month; 27 had had previously from one to six courses each of $28 \mathrm{~g}$. of sulphathiazole ; 19 patients received additional doses of the same amount of penicillin. In a total of 156 doses of penicillin there were only two instances of mild urticarial reaction. Tests of cure consisted of a direct microscopical examination and a culture of material from the cervix on a plate of Peizer's medium incubated at $37^{\circ} \mathrm{C}$. in $10 \% \mathrm{CO}_{2}$ at weekly intervals for 6 weeks. Of the 30 positive bacteriological results, 12 were obtained at the first examination, 4 at the second, 7 at the third, 3 at the fourth, 2 at the fifth, and 2 at the sixth. In 15 cases there was a history of a fresh exposure; of the 15 in which no such history was obtained all were detected within the first three examinations. Penicillin levels in 50 sera averaged not less than 0.025 unit per $\mathrm{ml}$. for a period of 15 to 20 hours. Of the 133 patients $67.7 \%$ were certainly cured, $11.3 \%$ possibly cured (1 to 5 negative tests), $9 \%$ probable failures (possible reinfections), and $9 \%$ definite failures; in 3\% no tests were carried out. Excluding those patients for whom information was incomplete, the cure rate was $95.5 \%$ (including those who had further treatment). Of the patients in whom treatment failed, more than half may have been re-infected. With a single dose alone' the cure rate was $89.9 \%$. Ten per cent. of the patients were found to have syphilis at the time or within 6 months of treatment.

T. E. Osmond

Residual Subacute and Chronic Prostatitis after Penicillin and Sulphonamide Therapy in Acute Gonorrhoa. Bourgault du Coudray, F. C. (1947). Brit. med. J., 2, 651 .

The author affirms " that subacute and chronic residual prostatitis after chemotherapy in acute gonorrhœa is of very widespread occurrence and gives rise to physical signs so long as it remains untreated." He considers that this sequel is equally common after penicillin or sulphonamides in those cases where the initial response to treatment is unfavourable. [No figures are given and the dosage of the sulphonamides or the penicillin used is not clearly indicated.] The purulent prostatic fluid from 8 cases was cultured and examined; the results were negative.

An account of 6 cases is given, in all but 1 of which a total dose of 150,000 units of penicillin was not exceeded. They appear to be chosen to show that pus cells may appear in the prostatic fluid very early in the course of 
acute primary gonococcal urethritis and can be seen sometimes before and sometimes very soon after apparently successful penicillin therapy.

Though the author states that, so far as he is aware, the condition he describes has not been given any prominence in current literature, "sulphonamide prostate " is well known to most venereologists and was described by Cokkinis and McElligott as long ago as 1938.

G. L. M. McElligott

Diagnosis and Penicillin Treatment of Gonococcal Cervical Metritis in the Puerperium. (Les métrites cervicales gonoccocciques au cours de la puerperalité (leur dépistage et leur traitement par la pénicilline).) Mayer, M., Delayre, -., and LANvin, -. (1947). Pr. méd., 55, 554.

Leucorrhœa in pregnancy ought never to be disregarded. By routine examination the authors have discovered gonococcal infection frequently in such cases. The gonococcus is more readily isolated during pregnancy, as the pregnancy appears to activate the infection and increase the virulence of the organism. Other organisms may be associated, particularly Trichomonas. Latent gonococcal infection of the cervix is often the cause of puerperal infection.

All such cases should be treated immediately the diagnosis is made, regardless of the stage of pregnancy, since treatment with penicillin has no adverse effect upon the pregnancy. The authors employ 200,000 units of penicillin a day in 3-hourly doses intramuscularly with the addition of local treatment, which they regard as essential. They inject $5 \mathrm{ml}$. of a solution containing 50,000 units of penicillin directly into the cervix and under the mucous membrane of the cervix and the canal. These local injections are given on alternate days and the patient is kept in bed. Treatment is continued until clinical signs of the disease have disappeared and two repeated cultures are negative.

When the infection is first discovered during labour or in the early days of the puerperium, the general treatment is given, but the local injections are omitted until the sixth day. All patients during pregnancy have a further course of treatment in the puerperium even if apparently cured, since dormant infection so readily lights up then.

L. W. Lauste

\section{GONORRHEA (Pathology)}

Liver Damage due to Gonorrhoea. (Beschadiging van de lever door gonorrhœ.) VAN SPANJE, A. J. H. (1947). Ned. Tijdschr. Geneesk., 4,2899.

A fatal case of acute yellow atrophy of the liver, preceded by persistent gonorrhœa, was observed in 1941 in a Rotterdam hospital. This prompted the author to investigate the liver function in uncomplicated gonorrhœa. Popper and Wiedemann ( $Z$. klin. Med., 1937, 131,258 ) had examined the records of over 2,000 dermatological patients and found that the incidence of icterus was $3 \cdot 5 \%$ among 1,000 patients with gonorrhœa and only $0.3 \%$ among the others. The present paper gives the results of the investigation of 104 patients-77 females and 27 males-with uncomplicated gonorrhœa. In 65 cases (group A) there was a first attack of gonorrhœa, in 28 (group B) a second attack, and in 11 (group C) syphilis was also present.

Tests showed that gonorrhœa affected liver function in a considerable number of cases. In most instances function became normal again after treatment ; nevertheless, in a certain number of cases serious disturbances persisted. Attention is drawn to group C, composed of patients in whom syphilis had been diagnosed but was untreated at the time of investigation; the majority of these had disturbances of liver function. A. Lilker

\section{A Study of Preinoculation and Preincubation Factors in the Primary Isolation of Neisseria gonorrhoeae.} Schubert, J. H., Bucca, M. A., and Thayer, J. D. (1947). 'J. vener. Dis. Inform., 28, 214.

Results of experiments to determine the most satisfactory methods for the pre-inoculation and preincubation of Neisseria gonorrhoee are described. In 145 established cases of gonorrhœa the cervical exudate was collected on a sterile cotton swab which was rolled on Peizer's plasma-hæmoglobin-agar medium and spread over its whole surface with a wire loop. The plates were examined after 48 hours' incubation at $35^{\circ} \mathrm{C}$. in a $10 \%$ carbon dioxide atmosphere. Direct transfer with a dry swab of the discharge from the patient to the culture plates in the clinic increased by $19 \%$ the number of positive cultures obtained $(96.5 \%)$, as compared with the number obtained $(77.2 \%)$ with the indirect transfer of discharge first suspended in broth before being inoculated on to the plate in the laboratory. Inoculations made in the clinic always gave results superior to those made in the laboratory, and the results achieved by placing the discharge directly on the culture medium were more accurate than those found after carrying the infected material in peptone solution. No advantage accrued when $0.1 \%$ cysteine was added to Peizer's medium, but holding the plates in an atmosphere of $10 \%$ carbon dioxide for 24 hours at room temperature before incubation produced $25.4 \%$ more positive cultures $(96.6 \%)$ than did similar plates without carbon dioxide $(71 \cdot 2 \%)$.

T. Anwyl-Davies

The Isolation of a Filterable Agent Pathogenic for Mice from a Case of Reiter's Disease. DunHAM, J., Rock, J., and BeLt, E. (1947). J. Urol., 58, 212.

Conjunctivitis was successfully produced in mice by intraperitoneal injections of filtered allantoic fluid previously infected with material from the urethra and conjunctiva of a 23-year-old white man suffering from Reiter's disease, with conjunctivitis, urethritis, and arthritis uninfluenced by sulphathiazole, penicillin, or neoarsphenamine. Some scanty urethral discharge was expelled into $5 \mathrm{ml}$. of heart infusion broth with $10 \%$ beef serum. A second specimen was obtained by inserting a conjunctival swab in the same medium. Both were frozen immediately and thawed at $37^{\circ} \mathrm{C}$. in the laboratory before inoculation of $0.01 \mathrm{ml}$. into the allantoic fluid of 12-day embryonated eggs, 12 eggs being used for each fluid. After being sealed with paraffin they were incubated for 48 hours and then chilled in a refrigerator for 2 hours. The allantoic fluid was then extracted, pooled, and filtered through a Seitz filter. Twenty mice were inoculated with the material derived from the eye, and 20 with that obtained from the urethra ; 20 served as controls. All were given, intraperitoneally, $0.1 \mathrm{ml}$. of one of four different saline dilutions of the allantoic filtrated $-60 \%$ of the mice injerted with material originating from a case of Reiter's disease, and none of the controls, developed conjunctivitis.

\section{R. R. Willcox}

The Aetiology of Reiter's Disease. (Recherches sur l'étiologie de la Maladie de Reiter.) PASTINSZKY, É. (1947). Acta derm.-venereol., Stockh., 27, 415.

After a short review of the European literature of Reiter's disease the author reports 7 cases. In each 
case diarrhœa preceded the attack by 3 to 4 weeks, but at that time bacteriological examination of the stools could not be carried out. In 2 patients sero-agglutination with Shigella dysenteria flexner gave titres of 1 in 200 to 1 in 400 . The bacteriological examinations of the conjunctival and urethral secretions were entirely negative. Lymphogranuloma venereum was excluded by the Frei test. The syndrome is considered to be either an allergic or parallergic reaction after bacillary infection of the intestines with later participation of the other organs. Urticaria, leucopenia with a shift to the left, local eosinophilia in conjunctival and urethral secretions, or general eosinophilia, which were observed in some of the cases, were thought to confirm the allergic ætiology. The arthritis was severe, chronic, and refractory to the administration of massive doses of salicylates or cineophen. Fever therapy (milk or sulphur injections), autohæmotherapy, calcium and ephedrine injections, glucose, and locally zinc sulphate or arenaline proved effective. [The " hypertherm" type of pyrotherapy has been found of use in treating resistant cases in Britain.]

$$
\text { G. W. Csonka }
$$

\section{OTHER VENEREAL DISEASE CONDITIONS}

Studies on Lymphogranuloma Venereum. V. The Action of some Antibiotic Substances and Sulfonamides in vitro and in vivo upon the Agents of Feline Pneumonitis and Lymphogranuloma Venereum. HAMRE, D., and RAKE, G. (1947). J. infect. Dis., 81, 175.

The authors tested the effect of certain sulphonamides and antibiotics on the agents of feline pneumonitis and lymphogranuloma venereum by treating infected yolksac suspensions. Sulphonamides had little effect in vitro and none in vivo on feline pneumonitis. Streptomycin and streptothricin had no effect on lymphogranuloma venereum or on feline pneumonitis. Penicillin in high concentrations was active against both, more so against lymphogranuloma venereum, protection being obtained in 77 to $89 \%$ of infections compared with $11 \%$ of feline pneumonitis ; the more pure the penicillin, the less active it appeared to.be. Penicillin was as effective against feline pneumonitis when given after 24 hours as when given with the infecting dose and was more effective as the dose of virus was decreased. Penicillin was most active when conditions were favourable for the growth of the viruses, tending at first to inactivate and then to inhibit them; when all the penicillin had disappeared growth was resumed, but at a relatively slow rate. Pure penicillin $G$ had no effect during the lag period of growth, but was active when growth began. Pure penicillin $F$ seemed to bring about a longer period of inhibition and to take longer to penetrate the cells, but when it did so it was frankly virucidal. Other penicillins, including $\mathbf{K}$, and high-grade commercial preparations, seemed to be only inhibitory. It is suggested that other types of penicillin may be found which will penetrate the cells quickly before being destroyed or excreted.

\section{T. E. Osmond}

\section{"Fever of Unknown Origin" due to Lymphogranuloma Venereum. Report of a Case with Diagnosis by the Use of Quantitative Complement-Fixation Tests. Luger, N. M. (1948). New Engl. J. Med., 238, 44.}

A 33-year-old negro, adequately treated the year before for latent syphilis, developed an intermittent fever of unknown origin. He had had short bouts of rigors and fever during the previous 9 months, during one of which he had been admitted to hospital without a diagnosis being made. At the time of the second admission chest radiographs, blood cultures, examinations for malarial parasites, and the usual agglutination tests proved negative though the Wassermann and Kahn reactions were still positive. The Frei test, however, gave a positive result and the complement-fixation test, with lygranum " $C F$ " antigen, was positive in a dilution of 1 in 640. Sulphadiazine was administered, $1 \mathrm{~g}$. 4-hourly for 2 weeks, the temperature returned to normal, and 4 months later the complement-fixation titre had fallen to 1 in 40 .

R. R. Willcox

General Manifestations of Lymphogranuloma Venereum. (Manifestations générales de la maladie de Nicolas et Favre.) le Coulant, P. (1948). Ann. Derm. Syph., Paris, 8, 5.

In 1925 Frei showed that pus from affected lymph nodes could be used as an antigen in an intradermal reaction which demonstrated the allergic state produced by lymphogranuloma venereum. Hellerstrom and Wasser showed in 1930 that inoculation of lymph-node extract into the brain of the monkey produced a specific encephalitis. A virus has been demonstrated and cultivated, and it has been found in cerebral tissue of infected animals. Frei's test is quite specific, but it should be noted that it is negative in the first 2 to 4 weeks of the disease and in anergic subjects (febrile illness, secondary syphilis, chancroid). Intravenous injection of Frei's antigen into a patient with lymphogranuloma venereum causes a specific reaction consisting of a rigor and, after about 6 hours, an elevation of temperature to $39^{\circ}$ or $40^{\circ} \mathrm{C}$. lasting 32 to 52 hours. This reaction is even more prècise than the intradermal test.

Apart from the well-known ano-genital lesions, general manifestations in the early stages of the disease include low fever, anorexia, headache, fatigue, and pains in the limbs, the whole picture resembling an acute rheumatism. There is often a leucocytosis of up to 12,000 and sometimes enlargement of liver and spleen. Cutaneous lesions may be nodular, gummatous, or ecthymatous ; and general eruptions, urticarial, scarlatiniform, papulovesicular, or erythematous (multiform or nodose) in type may also be seen. Parinaud has described a conjunctivitis with vegetations of the palpebral mucosa accompanied by pre-auricular adenitis which is believed to be caused by the virus of lymphogranuloma venereum. Rheumatic, arthritic, and osseous lesions have also been observed with lymphogranuloma venereum. Transitory meningeal reactions have often been described and there have been cases of graver nervous affections such as flaccid paraplegia, epileptiform attacks, and severe or even fatal meningo-encephalitis. The possibility that atypical pneumonia is sometimes caused by the virus of lymphogranuloma venereum has been suggested. The author reminds us that a diagnosis of lymphogranuloma venereum should be made only in the presence of lesions in one of the classical sites. and a positive Frei (or equivalent) test. James Marshall

Observations on Spinal Fluid in Lymphogranuloma Venereum. LeIfER, W. (1947). Arch. Derm. Syph., Chicago, 56, 699.

The observations refer to the results of spinal-fluid examination in 25 men with acute lymphogranuloma venereum. The duration of the inguinal lymphadenitis, which was bilateral in only 1 patient, varied from 3 to 28 days and exceeded 14 days in 10 cases. Actual suppuration of lymph nodes occurred in 12 patients and was associated with fever and headache. The headache was 
not severe, and there were no other symptoms or signs of involvement of the central nervous system. Lumbar puncture was performed after the clinical diagnosis had been confirmed by a positive reaction to the Frei test (with "lygranum") and thereafter sulphonamide therapy was started. The examination of the spinal fluid included, in all cases, a Wassermann test with 0.5 and $1.0 \mathrm{ml}$. of fluid, cell count, Pandy test, and colloidal gold test ; in 22 cases the total protein was also estimated.

These spinal-fluid examinations provided no evidence of virus invasion of the central nervous system. Biological false-positive Wassermann reactions in the spinal fluid were absent in this series, as is the case in published reports of lymphogranuloma meningo-encephalitis. This fact assumes great significance in differentiating between cases of acute syphilitic meningitis and lymphogranuloma meningo-encephalitis, which are often clinically indistinguishable and have in common changes in the cell and protein content and colloidal gold reactions of the spinal fluid.

S. M. Laird

The Antigenic Relationship of Lymphogranuloma Venereum and Psittacosis by Skin Test in Humans. Pollard, M., and WitKa, T. M. (1947). Tex. Rep. Biol. Med., 5, 288.

A psittacosis antigen suitable for carrying out skin tests was prepared by the following method. The P4 strain of virus was inoculated into the allantoic cavity of fertile eggs on the seventh day of incubation. Incubation was continued for a further 4 or 5 days at a temperature of $35^{\circ} \mathrm{C}$., when the chorio-allantoic fluid was harvested. The virus was inactivated by heating the fluid for 30 minutes at $56^{\circ} \mathrm{C}$., and deposited by centrifugation. It was then resuspended in one-tenth of the original volume of saline and used as the antigen. Tests with this antigen and with lygranum were carried out on patients with venereal disease in an Army hospital, the tests being performed on opposite arms. All 8 confirmed cases of lymphogranuloma venereum gave a severe reaction to the psittacosis antigen; 6 suspected cases, of which 2 were confirmed serologically, gave indefinite reactions; while 5 cases of penile ulcer, 8 cases of syphilis, and 3 suspected cases of syphilis were negative to both skin antigens. Lymphogranuloma venereum and psittacosis thus show an antigenic relation in the skin test, and this test is evidently not suitable for diagnosis when there is any possibility of the diseases co-existing.

\section{J. Bauer}

Action of Disinfectant, Chemotherapeutic, and Antibiotic Agents on the Organism of Granuloma Inguinale. RAKe, G., and Dunham, W. (1947). Amer. J. Syph., 31, 610.

A number of disinfectants and chemotherapeutic and antibiotic agents were mixed with serial dilutions of beefheart infusion and yolk from 5 to 6-day embryonated chicks previously infected with Donovania granulomatis. The mixtures were injected into other eggs which, after incubation for 5 days, were then examined; the strengths of the different solutions that would prevent infection of $50 \%$ of the eggs were calculated.

Of the disinfectants tried mercurous chloride, ethyl alcohol, and a mixture of copper sulphate and alkyl dimethyl benzylammonium chloride ("zephiran") were the most effective and phenol and formaldehyde the least. Tartar emetic in a concentration of $0.014 \mathrm{mg}$. per. $\mathrm{ml}$. gave the same results as concentrations of $0.091 \mathrm{mg}$. per $\mathrm{ml}$. of stibophen, $0.033 \mathrm{mg}$. per $\mathrm{ml}$. of bismuth and potassium tartrate, and $0.68 \mathrm{mg}$. per $\mathrm{ml}$. of dichloro- phenarsine hydrochloride. Sulphadiazine, sulphapyridine, and sulphamerazine all protected half of the eggs at a concentration of $5.2 \mathrm{mg}$. per $\mathrm{ml}$. Of the antibiotics, penicillin was the least successful, a concentration of $0.04 \mathrm{mg}$. per $\mathrm{ml}$. being required; but streptomycin and streptothricin gave values of 0.0062 and $0.0086 \mathrm{mg}$. per $\mathrm{ml}$. respectively.

In a comparison of crystalline penicillin $\mathrm{G}$, commercial penicillin, and an alumina adsorbate, significantly better results were obtained with penicillin $G$. Further tests with tartar emetic and sulphathiazole showed that the same amounts were necessary for $50 \%$ protection of the eggs if the injections were delayed for 2 hours after mixing with the infected yolk, but with streptomycin there was a very marked reduction in the dose required. It is suggested that this antibiotic should be given clinical trial. [This article was received for publication on May 3, 1947. Greenblatt and Dienst (J. vener. Dis. Inform., 1947, 28, 183) have published the very successful results in 59 patients so treated and studied for periods up to 8 months.]

R. R. Willcox

Studies on the Causal Agent of Granuloma Inguinale. Dienst, R. B., Reinstein, C. R., KüPPERMAN, H. S., and Greenblatt, R. B. (1947). Amer. J. Syph., 31, 614.

A small piece of tissue was taken from a typical granulating lesion of granuloma inguinale in a negro, washed with saline, ground, and teased; $0.25 \mathrm{ml}$. of seven serial dilutions was injected into 14 eggs. Twelve embryos died from bacterial contamination within 72 hours, but uncontaminated Donovan bodies were found on the eighth day in 2. Teased, washed portions of another piece were incubatéd on agar slants for 48 hours and those free from secondary contamination were injected into 12 eggs. Only one embryo survived beyond 5 days ; Donovan bodies and diphtheroids were found in it on the eleventh day. Another series of 8 eggs was injected with similar material, except that penicillin was added to the saline used for washing., Six embryos died within 72 hours, but 2 contained uncontaminated Donovan bodies on the eighth and eleventh days respectively. One of these was subcultured through six passages and the culture from the third passage was injected into the inguinal region of a negro. A small nodule formed at once at the site of injection; after it had increased in size for 16 days it was removed surgically and Donovan bodies were found within it. When a direct tissue transplant was made from lesion to volunteer local induration appeared after 8 days; by the fortieth day the lesion was fluctuant and Donovan bodies were demonstrated in the aspirated fluid. A typical lesion later developed. If tissue suspensions were first filtered through a Berkefeld $N$ candle no infection could be transmitted either to a human subject or to embryonated eggs.

R. R. Willcox

Streptomycin in the Therapy of Granuloma Inguinale. Kupperman, H. S., Greenbi.ATt, R. B., Dienst, R. B. (1948). J. Amer. med. Ass., 136, 84.

The authors describe the results of treating 48 patients suffering from granuloma inguinale with streptomycin, and in an addendum give details of a further 43 patients. Thirty-five of the patients in the first series had had the disease for long periods and had been treated with various antimony preparations. Donovan bodies were demonstrated in all cases before streptomycin was started. Doses of the antibiotic varied from 3.3 to $60 \mathrm{~g}$., with an average of $20 \mathrm{~g}$. The drug was given every 4 hours for 
5 to 62 days, and the optimum dose appeared to be $20 \mathrm{~g}$. in 5 days. Toxic reactions were few and included pruritus, which was controlled by diphenhydramine hydrochloride, and urticarial dermatitis ; no involvement of the eighth nerve was noted. Donovan bodies tended to disappear 2 to 11 (average 6) days after treatment was started ; lesions began to heal within 24 to 48 hours and were usually completely healed within 4 weeks of the end of treatment ; pain generally disappeared within 24 to 36 hours. Relapses occurred in 3 of the 48 patients, 2 of whom received only $4 \mathrm{~g}$. of the antibiotic; the third became resistant but reacted to "anthiomaline." The average period of observation was 9 weeks. Three cases are described in detail, and six figures show the lesions in 2 patients before and after treatment. It is concluded that streptomycin is effective in the therapy of granuloma inguinale.

T. E. Osmond

Notes on the Epidemiology of Granuloma Inguinale. Clarke, C. W. (1947). J. vener. Dis. Inform., 28, 189.

According to Greenblatt there are 10,000 cases of granuloma inguinale in the United States. The author found that 32 out of 48 State and Territorial health departments required notification of the condition, which is more prevalent in south-eastern States. Of cases reported in 20 States in 1943 , only $8 \%$ were in white persons ; $58 \%$ were in males. Granuloma inguinale constituted $2.4 \%$ of all venereal infections in Negro troops over a period of 17 months.

The evidence for and against its venereal origin is presented. No adequate study has been made of the epidemiology of the condition, nor is its incubation period known ; in 55 out of 60 cases the incubation period ranges from 3 to 40 days.

Maurice McElligott

Investigations on Immunity to Yaws in Man. (Pesquisas sobre a imunidade da framboesia tropica no homem.) Guimaraes, F. N. (1947). Mem. Inst. Osw. Cruz., 44, 649.

From the second to the eighth month after injection there is a high degree of resistance to reinfection with yaws. Resistance depends on the presence of skin lesions : if these are cured the patient can be reinoculated and acquire yaws in the usual incubation period. In untreated cases from about the tenth month to 4 years after primary infection there is partial immunity, for only a localized atypical lesion develops at the site of re-inoculation. This partial immunity is unaffected by treatment. After the fifth year of primary infection re-inoculation causes a local necrotic lesion and an exacerbation of the tertiary lesions. This reaction is not modified by treatment. From the epidemiological point of view it is advisable to await the secondary phase before beginning treatment, otherwise if the subjects return to an endemic focus they will become reinfected.

[This last conclusion has also been reached by the members of many tribes in West Africa who refuse to allow their children to be treated until they have developed a well-marked secondary rash.] G. M. Findlay

Mal del Pinto" or " Carate" and its Treatment with
Chlorhydrate (Mapharsen). Varela, G., and AviLA, C. (1947). Amer. J. trop. Med., 27, 663.

The authors failed to grow. $T$. carateum on anaerobic media, chorio-allantoic membrane, or the yolk of fertilized eggs, but good results were obtained with cultures of nerve tissues of mouse embryos which, when injected into the skin of a patient with pinta, produced an allergic reaction within 10 minutes but no subsequent lesions within 6 months. They were unable to reproduce Blanco's experiment of positive intradermal inoculation of the rabbit with transmission of the infection to man. Of 805 individuals studied, $56.2 \%$ of children of affected parents also had the disease, while $43.5 \%$ of offspring of healthy parents were affected. Body maps of the sites of lesions in 200 patients are shown. Patients were treated by injections of $0.04 \mathrm{~g}$. of " mapharsen " twice weekly for 5 to 15 injections. Of 66 cases observed for periods up to 1 year, no change was noted in 6 and only partial resolution of the hyperchromic lesions in the remainder. In only $4 \%$ did the degree of positivity of the Kahn test diminish. 